А. М. Коржов ${ }^{1}$, А. М. Артеменко ${ }^{2}$, О. В. Костянець ${ }^{1}$, О. В. Струцінський ${ }^{3}$

${ }^{1}$ Харківській національний університет Повітряних Сил імені Івана Кожедуба, Харків, Україна

${ }^{2}$ Генеральний штаб Збройних Сил України, Київ, Україна

${ }^{3}$ B/ч 2533, Дніпро, Україна

\title{
ОСОБЛИВОСТІ БАГАТОЧАСТОТНИХ СИГНАЛІВ ТА ЇХ ВИКОРИСТАННЯ В РЛС ВИЯВЛЕННЯ МАЛОВИСОТНИХ ЦІЛЙ НАД МОРЕМ
}

\begin{abstract}
Предметом вивчення в статті є багаточастотні (БЧ) радіолокаційні станції (РЛС) виявлення маловисотних цілей над морем в умовах перешкод. Метою $є$ підвищення ефективності БЧ систем виявлення цілей в умовах перешкод. Завдання: аналіз БЧ сигналів при послідовному формуванні їх складових з використанням аналітичних виразів для довільного БЧ сигналу; математичне моделювання двовимірних кореляційних функцій для різних фазочастотних кодів МЧ сигналу; розробити рекомендації по застосуванню в РЛС виявлення маловисотних цілей. Використовуваними методами є: методи статистичної радіотехніки, теорії вірогідності і математичної статистики. Отримані наступні результати. Отримані частотно-часова діаграма, амплітудно-частотний спектр (АЧС), двомірна кореляційна функція невизначеності, а також нормовані автокореляційна (АКФ) і частотнокореляційна (ЧКФ) функції для різних фазочастотних кодів БЧ сигналу. Проаналізовані смуга когерентності, тривалість головної пелюстки і рівень бічних пелюсток АКФ імпульсного БЧ сигналу із складовими без внутрішньої модуляції та імпульсного БЧ сигналу з лінійночастотномодульованими складовими з різними кодами по частоті і фазі, а також різною шириною спектру дискрет і різним їх рознесенням по частоті. Висновки. Проведений порівняльний аналіз основних видів послідовних БЧ сигналів дозволяє сформулювати рекомендації відносно їх застосування в РЛС виявлення маловисотних цілей в різних умовах перешкодової обстановки. А саме, послідовні БЧ з суцільним АЧС доцільніше використовувати для підвищення характеристик виявлення маловисотних цілей в радіолокаційному каналі (РЛК) над морем у флуктуаційних перешкодах, а сигнали огинаюча та АЧС яких не суцільні доцільніше використовувати в умовах навмисних нестаціонарних в часі і нерівномірних по частоті перешкодах. Послідовні БЧ сигнали з прямокутною огинаючою та АЧС, що складається з АЧС частотних складових, які перетинаються, доцільніше використовувати для підвищення характеристик виявлення маловисотних цілей над морем в РЛК з модулюючими перешкодами.
\end{abstract}

Ключові слова: багаточастотні сигнали, послідовні імпульсні багаточастотні сигнали, радіолокаційна станція виявлення, маловисотна ціль, когерентність сигналів.

\section{Вступ}

Постановка проблеми. На сучасному етапі розвитку радіотехнічних засобів в умовах масованого нальоту із застосуванням всього арсеналу засобів вогневого придушення і радіоелектронної боротьби актуальним $\epsilon$ виявлення маловисотних цілей, наприклад, ударних або розвідувальних безпілотних літальних апаратів, гелікоптерів, некерованих ракет, літаків та повітряних шарів. Це завдання може бути вирішене 3 використанням високо-інформаційних перешкодо-захищених радіолокаційних станцій $[1$, 3-6]. Як відомо [5, 6], інформативність радіолокаційних станцій (РЛС) визначається, у першу чергу, базою зондувальних сигналів $D=\Delta f_{c} \cdot \tau_{c}\left(\Delta f_{c}, \tau_{c}-\right.$ ширина спектра та тривалість зондуючого сигналу). Найбільш просто більші значення $D$ реалізуються за допомогою складних сигналів 3 внутріімпульсною або міжперіодною модуляцією (маніпуляцією) амплітуди, фази, частоти [8].

Аналіз останніх досліджень і публікацій. Аналіз $[1,2]$ показує, що виявлення маловисотних цілей в тропосферному радіолокаційному каналі (РЛК) може бути покращено при використанні складених по частоті, багаточастотних (БЧ) сигна- лів. Це пов'язано з тим, що в таких умовах поширення радіохвиль «луна-сигнали» та їх амлітудночастотні спектри (АЧС) постійно змінюються (флуктують) при відносному руху елементів РЛК. Негативний вплив флуктуацій відбитих сигналів на характеристики РЛС може бути усунутий або, принаймні, зменшений, якщо вдасться яким-небудь чином добитися їхнього згладжування. Одним зі способів згладжування $€$ застосування складних сигналів. Прикладом такого складного сигналу можуть бути БЧ сигнали $[6,8]$. Реалізація переваг багаточастотних сигналів в значній мірі залежить не тільки від характеру флуктуацій відбитих від цілі сигналів, а ї від їх параметрів й засобів обробки.

Виграш у дальності виявлення маловисотних цілей у тропосферному РЛК БЧ РЛС може складати до $30 \%$ у порівнянні з одночастотною РЛС при тих же потужностях випромінювання та ЕПР цілі $[2,7]$. Але при багаточастотній роботі може виникати протиріччя між вимогами до параметрів зондуючого сигналу й небажаними наслідками від використання такого сигналу для локації маловисотних цілей (МЦ) у тропосферному радіохвилеводі. У результаті цього реалізовані тактико-технічні характеристики РЛС можуть виявитися значно гіршими потенційно можливих. Реалізація переваг багаточастотної РЛС у 
значній мірі залежить від відношення сигнал-шум (СШ) на вході приймача РЛС і вибору виду і параметрів зондуючого сигналу.

Тому в статті проведено порівняння основних видів послідовних багаточастотних сигналів і сформульовані рекомендації щодо їх застосування в радіолокаційних станціях виявлення маловисотних цілей в умовах перешкод.

Мета статті: Провести порівняння основних видів послідовних багаточастотних сигналів і сформулювати рекомендації щодо їх застосування в радіолокаційних станціях виявлення маловисотних цілей в умовах перешкод.

\section{Виклад основного матеріалу}

На основі загальноприйнятих відомостей [3, 4, 7], можна вважати, що БЧ сигнали складають окремий вид радіолокаційних сигналів і мають загальні властивості. Вони можуть розділятися на сигнали 3 одним ступенем ортогональності (паралельні БЧ сигнали) та сигнали 3 подвійним ступенем ортогональності (послідовні БЧ сигнали).

Проведемо аналіз БЧ сигналів при послідовному формуванні їх складових. Ці сигнали мають енергетичний виграш при порівнянні з БЧ сигналами, у яких складові формуються паралельно, що дозволяє більш просто реалізувати БЧ сигнали 3 більшою базою і отримати кращі характеристики виявлення маловисотних цілей в умовах перешкод [8].

Аналіз властивостей імпульсних багаточастотних послідовних сигналів (БЧ ПОС) проведемо за виразами для довільного БЧ сигналу, його комплексної обвідної, спектральної щільності комплексних обвідних узагальненого БЧ сигналу та однієї частотної дискрети, двовимірної кореляційної функції комплексної обвідної узагальненого БЧ сигналу, а також автокореляційної функції (АКФ) та частотнокореляційної функції (ЧКФ) узагальненого БЧ сигналу $[8,9]$. Комплексну огинаючу БЧ ПОС для вагової функції $A_{\gamma}(f)=1$ можливо записати:

$$
\begin{gathered}
\dot{U}_{\text {БЧC }}(t)=\sum_{\gamma=1}^{N} p_{\gamma}(t) U_{\gamma}\left[t-(\gamma-1) \tau_{0}\right] \times \\
\quad \times \exp \left[j 2 \pi\left(\gamma \mathrm{p}_{\gamma}(f)-1\right) \Delta f_{\gamma} t+\varphi_{\gamma}\right]=, \\
=\sum_{\gamma=1}^{N} U_{\gamma}\left[t-\Delta \tau_{\gamma}\right] \exp \left[\mathrm{p}_{\gamma}\left(j 2 \pi \Delta f_{\gamma} t\right)\right]
\end{gathered}
$$

де г $\in \overline{1, \mathrm{~N}}$ - дійсне ціле число; $\mathrm{N}$ - кількість складових; $\tau_{0}$ - тривалість одної складової БЧ сигналу; Д $f_{\Gamma}$ - зміщення $\gamma$-тої складової сигналу за частотою; $\varphi_{\Gamma}-$ початкова фаза $\gamma$ складової; $\Delta \tau_{\Gamma}-$ затримка $\gamma$ тої складової сигналу за часом; $p_{\gamma}$-амплітудночасочастотний код БЧ сигналу; $U_{\gamma}(\mathrm{t})-$ комплексна огинаюча однієї частотної складової БЧ ПОС.

В свою чергу спектр комплексної огинаючої БЧ ПОС може бути представлений у вигляді:

$$
\begin{gathered}
\dot{G}_{\text {БЧC }}(2 \pi f)=\sum_{\gamma=1}^{N} \dot{G}_{\gamma}\left[2 \pi f-(\gamma-1) 2 \pi \Delta f_{\gamma}\right] \times \\
\times \exp \left[-j 2 \pi f(\gamma-1) \Delta \tau_{\gamma}+\varphi_{\gamma}\right]= \\
=\sum_{\gamma=1}^{N} \dot{G}_{\gamma}\left[2 \pi\left(f-\Delta f_{\gamma}\right)\right] \cdot \exp \left[-j 2 \pi f \Delta \tau_{\gamma}+\varphi_{\gamma}\right]
\end{gathered}
$$

де $G_{\gamma}(\mathrm{f})$ - АЧС однієї частотної складової БЧ ПОС.

Виконавши перетворення (2), отримаємо двомірну кореляційну функцію невизначеності (ДКФН) комплексної огинаючої цього сигналу:

$$
\begin{gathered}
R(\tau, F)=\frac{1}{N} \sum_{\gamma=1}^{N} \sum_{\mu=1}^{N} R_{0}\left(\tau_{\gamma, \mu}, F_{\gamma, \mu}\right) \cdot \exp \left[j 2 \pi \Delta f_{\gamma} \tau\right]= \\
=\frac{1}{N} \sum_{\gamma=1}^{N} \sum_{\mu=1}^{N} R_{0}\left[(\tau-(\gamma-\mu)) \Delta \tau_{\gamma} F+(\gamma-\mu) \Delta f_{\gamma}\right] \times \\
\times \exp \left[j 2 \pi \varepsilon_{R}(\tau, F)\right],
\end{gathered}
$$

де $R_{0}\left(\tau_{\gamma, \mu}, F_{\gamma, \mu}\right)$ - ДКФН комплексної огинаючої однієї частотної складової БЧ ПОС;

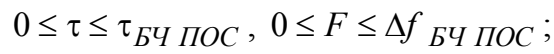

$F_{\gamma, \mu}=F+(\gamma-\mu) \Delta f_{\gamma}-$ зміщена частота Доплера;

$\tau_{\gamma, \mu}=\tau-(\gamma-\mu) \tau_{\gamma}-$ зміщена затримка.

$\varepsilon_{R}(\tau, \mathrm{F})=(\mu-1) \Delta \mathrm{f}_{\gamma} \tau+(\gamma-1) \Delta \tau_{\gamma} F-(\gamma-\mu) \Delta \mathrm{f}_{\gamma} \Delta \tau_{\gamma}-$ фазовий множник;

$$
\begin{gathered}
R(\tau, 0)=\frac{1}{N} \sum_{\gamma=1}^{N} \sum_{\mu=1}^{N} R_{0}\left(\tau_{\gamma, \mu}, 0\right) \exp \left[j 2 \pi \Delta f_{\gamma} \tau\right], \\
R(0, F)=\frac{1}{N} \sum_{\gamma=1}^{N} \sum_{\mu=1}^{N} R_{0}\left(0, F_{\gamma, \mu}\right)-
\end{gathered}
$$

АКФ і ЧКФ комплексної огинаючої БЧ ПОС.

На основі виразів (3) та (4) було проведене математичне моделювання за допомогою пакета математичних програм (Mathcad) i отримано часочастотна діаграма, АЧС, тіло невизначеності $\mathrm{R}(\tau, \mathrm{F})$, нормовані відносно $\mathrm{R}(0,0)$ модулі АКФ $\mathrm{R}(\tau, 0)$ і ЧКФ $\mathrm{R}(0, \mathrm{~F})$ для різних $p_{\gamma}(a, \varphi, f)$. В якості частотних складових використовувалися прості імпульсні та ЛЧМ сигнали. Огинаючі БЧ ПОС прямокутні $\left(p_{\gamma}(a)=1, A_{\gamma}(\mathrm{t})=1\right)$. Для спільності, кількість частотних складових становила $\mathrm{N}=5$. Аналізувалася смуга когерентності $W_{S}$, тривалість головної пелюстки АКФ $\tau_{2 n}$ і рівень іï бокових пелюсток $\frac{U_{б n}}{U_{\max }}$.

Проведено порівняння основних видів послідовних БЧ сигналів і сформульовані рекомендації щодо їх застосування в РЛС виявлення маловисотних цілей в умовах перешкод.

Досліджувалися наступні послідовні багаточастотні сигнали:

1. Імпульсний БЧ сигнал, якій за часом складався $3 N$ складових без внутрішньої модуляції. В якості кодів використовувалися: за частотою 
$\left[p_{\gamma}(f)\right]$ - рівномірний код або код Костасу, за фа-

зою $\left[p_{\gamma}(\varphi)\right]$ - рівномірний код або код Баркеру.

2. Імпульсний БЧ сигнал, якій за часом складався $3 N$ ЛЧМ складових. В якості кодів за фазою $\left[p_{\gamma}(\varphi)\right]$ використовувалися рівномірний код або код Баркеру.

3. Імпульсний БЧ сигнал, якій за часом складався $3 N$ ЛЧМ складових. В якості кодів використовувалися: за частотою $\left[p_{\gamma}(f)\right]$ - рівномірний код або код Костасу, за фазою $\left[p_{\gamma}(\varphi)\right]$ - рівномірний код або код Баркеру.

4. Імпульсний БЧ сигнал, якій за часом складався $3 N$ ЛЧМ складових. Але ширина спектра сигналу приблизно дорівнює ширині спектра однієї дискрети, а зміщення дискрет за частотою значно менше ширини спектра однієї дискрети. В якості кодів використовувалися: за частотою $\left[p_{\gamma}(f)\right]$ рівномірний код або код Костасу, за фазою $\left[p_{\gamma}(\varphi)\right]$ - рівномірний код або код Баркеру. Результати моделювання наведено на рис. 1.

Аналіз отриманих результатів показує, що для послідовних БЧ сигналів, як і для паралельних БЧ сигналів, за інтегральним й похідним критерієм більшу смугу когерентності $W_{S},\left(W_{S}^{2 n}\right)$ мають БЧ сигнали із суцільним АЧС, а більший час когерентності $T_{S},\left(T_{S}^{2 n}\right)$ - БЧ когерентні сигнали із прямокутною обвідною. Це можливо поясніти тим, що такі сигнали мають одну зону високої когерентності за часом та частотою. Із послідовних БЧ сигналів, що мають суцільний АЧС, більшу смугу когерентності мають БЧ ПР сигнали. Смуга когерентності БЧ ЛЧМ сигналів близька до смуги когерентності БЧ ПР сигналів. Форма зони когерентності за часом залежить від ваг $A_{\gamma}(\mathrm{f})$, а за частотою від ваг $A_{\gamma}(\mathrm{t})$. Рівень бокових пелюсток $\left(U_{\sigma n} / U_{\max }\right)$ послідовних БЧ сигналів із суцільним АЧС співпадає з рівнем бокових пелюсток паралельних БЧ сигналів із суцільним АЧС. Вибір коду $p_{\gamma}(a, \varphi, f)$ дозволяє додатково керувати формою зони когерентності і рівнем бокових пелюсток. Такі БЧ сигнали доцільно використовувати для покращення виявлення маловисотних цілей у радіолокаційному каналі над морем в флуктуаційних перешкодах [9].

Для сигналів обвідна і АЧС яких не суцільні за інтегральним критерієм смуга когерентності $\left(W_{S}\right)$ й час когерентності $\left(T_{S}\right)$ зменшується пропорційно їх шпаруватості. Це можливо поясніти тим, що такі сигнали мають декілька зон високої когерентності за часом та частотою. Додаткові зони когерентності можна трактувати як появу "далеких" бічних пелюсток АКФ і ЧКФ сигналу, що не змінює тривалість та смугу їх головної пелюстки. $\mathrm{f}(\mathrm{t}) \uparrow$


$\mathrm{R}(\tau, 0)$

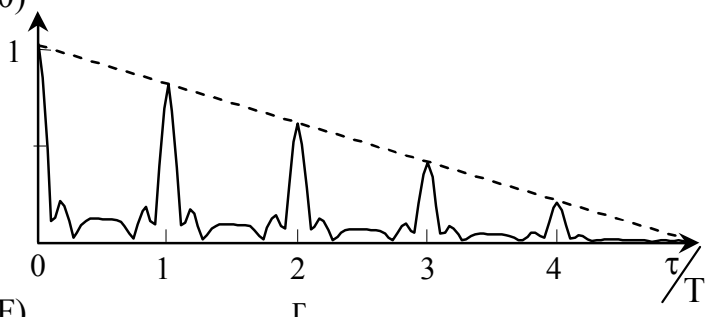

$\mathrm{R}(0, \mathrm{~F})$

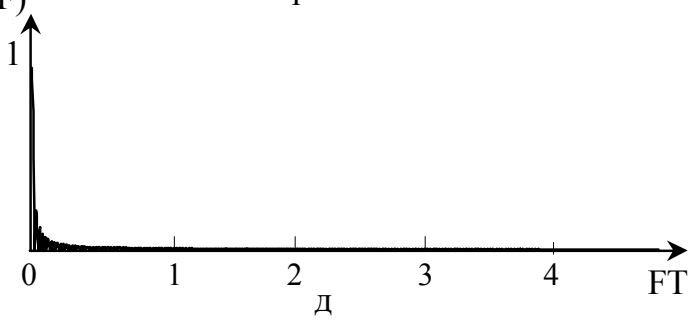

Рис. 1. Частотно-часова діаграма (а); АЧС (б); двовимірна кореляційна функція (в); АКФ (г) і ЧКФ (д) послідовного БЧ ЛЧМ сигналу

Тому за похідним критерієм оцінки смуги $\left(W_{S}^{2 n}\right)$ і часу когерентності $\left(T_{S}^{2 n}\right)$ визначаються 
лише тривалістю сигналів $\left(\tau_{б ч}\right)$ і шириною їх АЧС $\left(\Delta F_{б ч}\right)$ відповідно. Кодування по частоті і фазі не

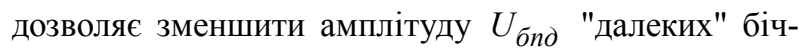
них пелюсток АКФ і ЧКФ послідовних БЧ сигналів обвідна і АЧС яких не суцільні. Рівень "ближніх" бічних пелюсток АКФ послідовних БЧ сигналів визначається видом вагової функції $A_{\gamma}(f)$, а рівень їх "ближніх" бічних пелюсток ЧКФ - видом вагової функції $A_{\gamma}(t)$ й при $\mathrm{N} \rightarrow \infty$ досить швидко прагне до рівня бічних пелюсток одночастотного сигналу 3 відповідною частотною або часовою ваговою функцією. "Ближні" бічні пелюстки АКФ і ЧКФ сигналу можна зменшити традиційними (ваговими) методами або кодуванням частотних складових сигналу по частоті і фазі. Такі БЧ сигнали доцільно використовувати для покращення виявлення маловисотних цілей у радіолокаційному каналі над морем в умовах навмисних нестаціонарних в часі і нерівномірних по частоті перешкодах [9].

Для послідовних БЧ сигналів 3 прямокутною обвідною і АЧС, що складається 3 АЧС частотних складових, які перетинаються, коефіцієнт перекриття $K_{n e p}=\Delta F_{0} / \Delta f_{\gamma} \geq 1$, за інтегральним критерієм смуга когерентності $\left(W_{S}\right)$ визначається тривалістю сигналу $\left(\tau_{б ч}\right)$, а час когерентності $\left(T_{S}\right)$ зменшується пропорційно $\overline{\left(\Delta F_{б ч}\right)} / \Delta F_{б ч} \leq 1$, де $\overline{\left(\Delta F_{б ч}\right)}$ ефективна смуга АЧС сигналу. Нерівномірність АЧС призводить до появи додаткових часових зон когерентності ("далеких" бічних пелюсток АКФ). Амплітуда "далеких" бічних пелюсток $U_{\text {бпд }}$ залежить від ступеня перекриття АЧС частотних складових сигналу. Кодування по фазі не дозволяє зменшити "далекі" бічні пелюстки АКФ. Основним методом їх зменшення можна вважати кодування по частоті за кодами Костасу, при яких $\left(U_{\text {бпд }} / U_{\max }\right) \leq-15[\partial Б]$.
Рівень "ближніх" бічних пелюсток АКФ послідовних БЧ сигналів $U_{\text {бn }}$ визначається ступенем перекриття спектрів складових сигналу і слабо залежить від частотної вагової функції $A_{\gamma}(f)$, а рівень їх "ближніх" бічних пелюсток ЧКФ - видом вагової функції $A \gamma(t)$. За похідним критерієм оцінки смуги $\left(W_{S}^{2 n}\right)$ і часу когерентності $\left(T_{S}^{2 n}\right)$ визначаються тривалістю сигналів $\left(\tau_{б ч}\right)$ i шириною їх АЧС $\left(\Delta F_{б ч}\right)$, відповідно. Такі сигнали доцільно використовувати для покращення виявлення маловисотних цілей над морем у радіолокаційному каналі з модулюючими перешкодами [7].

Для РЛС виявлення маловисотних цілей в радіолокаційному каналі над морем в існуючій завадовій обстановці БЧ ЛЧМ сигнали більш універсальні ніж БЧ ПР сигнали. Це пов'язано з тим, що ширина АЧС ЛЧМ сигналів з великою базою мало залежить від їх тривалості. Тому можна вважати їх базовими. Це тим більш справедливо, якщо враховувати особливості формування таких сигналів [9].

\section{Висновки}

Проведений порівняльний аналіз основних видів послідовних багаточастотних сигналів за результатами моделювання дозволяє стверджувати, що послідовні БЧ сигнали із суцільним АЧС доцільно використовувати для покращення виявлення маловисотних цілей у радіолокаційному каналі над морем в флуктуаційних перешкодах, а сигнали обвідна i АЧС яких не суцільні доцільно використовувати в умовах навмисних нестаціонарних в часі і нерівномірних по частоті перешкодах. Послідовні БЧ сигналі з прямокутною обвідною і АЧС, що складається 3 АЧС частотних складових, які перетинаються, доцільно використовувати для покращення виявлення маловисотних цілей над морем у радіолокаційному каналі з модулюючими перешкодами.

\section{СПИСОК ЛІТЕРАТУРИ}

1. Кеннеди Р. Каналы связи с замиранием и рассеиванием / Р. Кеннеди. - М.: Сов. радио, 1973. - 304 с.

2. Калинин А. И. Распространение радиоволн на трассах наземных и космических радиолиний. - М.: Связь, 1979. - 296 с.

3. Варакин Л. Е. Системы связи с шумоподоными сигналами / Л. Е.Варакин. - М.: Радио и связь, 1985. - 384 с.

4. Теория обнаружения сигналов / П. С. Акимов, П. А. Бакут, В. А. Богданович и др. - М.: Радио и связь, 1984. -440 с.

5. Ван-Трис Г. Теория обнаружения, оценок и модуляции: Пер. с англ. т.3 / Г. Ван-Трис. - М.: Сов. Радио, 1977. - 662 с.

6. Радиоэлектронные системы: Основы построения и теория. Справочник / Под ред. Я. Д. Ширмана. - М.: ЗАО "МАКВИС", 1998. - 828 с.

7. Модель дискретного радиолокационного канала с рассеиванием по времени и частоте / И. Г. Леонов, А. Н. Коржов, Р. Н. Животовский, А. А. Радюков // Сб. научн. тр. ЦНИИ ВВТ ВС Украины, вип. 1(52). - К., 2014. - С. 189-195.

8. Методика сравнительного анализа многочастотных сигналов / И. Г. Леонов, А. Н. Коржов, Р. М. Животовский, В. Н. Петрушенко // Системи озброєння та військова техніка. - Харків: ХУПС, 2013, № 1 (33). - С. 22-25.

9. Леонов І. Г. Компенсація активних прицільних завад у разі використання багаточастотного сигналу / I. Г. Леонов, А. Є. Присяжний // Системи озброєння і військова техніка. - Х.: ХУ ПС, 2006. - № 3 (7). - С. 42 - 45.

\section{REFERENCES}

1. Kennedi, R. (1973), Channels of communication with stopping beating and dispersion, Sov. Radio, Moscow, $304 \mathrm{p}$.

2. Kalinin, A.I. (1979), Distribution of radio waves on the routes of surface and space radio link, Svyaz, Moscow, $296 \mathrm{p}$.

3. Varakin, L.Ye. (1985), Communication networks with noise-like signals, Radio i svyaz, Moscow, 384 p.

4. Akimov, P.S., Bakut, P.A. and Bogdanovich, V.A. (1984), Theory of finding out signals, Radio i svyaz, Moscow, 440 p.

5. Van-Tris, G. (1977), Theory of discovery, estimations and modulation, Sov. Radio, Moscow, 662 p.

6. Shirman, Ya.D. (1998), Radio electronic systems: Bases of construction and theory, ZAO "MAKVIS", Moscow, 828 p. 
7. Leonov, I.G., Korzhov, A.N., Zhivotovskiy R.N., and Radyukov, A.A. (2014), "Model diskretnogo radiolokatsionnogo kanala s rasseivaniem po vremeni i chastote" [Model of discrete radio-location channel with dispersion at times and to frequency], Sbornik nauchnykh trudov TsNII VVT VS Ukrainy, TsNII VVT VSU, Kiev, № 1(52), pp.189-195.

8. Leonov, I.G., Korzhov, A.N., Zhivotovskiy, R.M. and Petrushenko, V.N. (2013), "Metodika sravnitelnogo analiza mnogochastotnykh signalov" [Method of comparative analysis of multifrequency signals], Zbirnyk naukovykh prats. Systemy ozbroiennia ta viiskova tekhnika, KhUPS, Kharkiv, №. 1(33), pp. 22-25.

9. Leonov, I.G. and Prysiazhnyi, A.Ie. (2006), "Kompensatsiia aktyvnykh prytsilnykh zavad u razi vykorystannia bahatochastotnoho syhnalu" [Indemnification of active aiming hindrances is in the case of the use of multifrequency signal], Systemy ozbroiennia i viiskova tekhnika, KhU PS, Kharkiv, №. 3(7), pp.42-45.

Рецензент: д-р техн. наук, проф. Л. Ф. Купченко, Харківський національний університет Повітряних Сил імені Івана Кожедуба, Харків Received (Надійшла) 6.03.2018 Accepted for publication (Прийнята до друку) 23.04.2018

\title{
Особенности многочастотных сигналов и их использование в РЛС обнаружения маловысотных целей над морем
}

\author{
А. Н. Коржов, А. М. Артеменко, О. В. Костянец, О. В. Струцинский
}

Предметом изучения в статье являются многочастотные (МЧ) радиолокационные станции (РЛС) обнаружения маловысотных целей над морем в условиях помех. Целью является повышение ефективности МЧ систем обнаружения целей в условиях помех. Задачи: анализ МЧ сигналов при последовательном формировании их составляющих с использованием аналитических выражений для произвольного МЧ сигнала; математическое моделирование двумерных корреляционных функций для разных фазочастотных кодов МЧ сигнала; разработать рекомендации по применению в РЛС обнаружения маловысотных целей. Используемыми методами являются: методы статистической радиотехники, теории вероятностей и математической статистики. Получены следующие результаты. Получены время-частотная диаграмма, амплитудно-частотный спектр (АЧС), двухмерная корреляционная функция неопределенности, а также нормированные автокорреляционная (АКФ) и частотнокорреляционные (ЧКФ) функции для разных фазочастотных кодов МЧ сигнала. Проанализированы полоса когерентности, длительность главного лепестка и уровень боковых лепестков АКФ импульсного МЧ сигнала с составляющими без внутренней модуляции и импульсного МЧ сигнала с линейночастотно модулированными составляющими с разными кодами по частоте и фазе, а также разной шириной спектра дискрет и разным их разносом по частоте. Выводы. Проведенный сравнительный анализ основных видов последовательных МЧ сигналов позволяет сформулировать рекомендации относительно их применения в РЛС обнаружения маловысотных целей в различных условиях помеховой обстановки. А именно, последовательные МЧ со сплошным АЧС целесообразнее использовать для улучшения характеристик обнаружения маловысотных целей в радиолокационном канале (РЛК) над морем в флуктуационных помехах, а сигналы огибающая и АЧС которых не сплошные целесообразнее использовать в условиях преднамеренных нестационарных во времени и неравномерных по частоте помехах. Последовательные МЧ сигналы с прямоугольной огибающей и АЧС, что состоит из АЧС частотных составляющих, которые пересекаются, целесообразнее использовать для улучшения обнаружения маловысотных целей над морем в РЛК с модулирующими помехами.

Ключевые слова: многочастотные сигналы, последовательные импульсные многочастотные сигналы, радиолокационная станция обнаружения, маловысотная цель, когерентность сигналов.

\section{Peculiarities of multifrequency signals features and their using in radars for detecting of low-altitude targets over sea \\ A. Korzhov, A. Artemenko, O. Kostyanets, O. Strutsinskyi}

The subject matter of the article is multifrequency radars for detecting of low-altitude targets over sea. The goal is to increase the efficiency of multifrequency radars for detecting of low-altitude targets over sea. The tasks to be solved are: analyzing multifrequency signals in the sequential formation of their components with the use of analytical formulas for a random multifrequency signal; mathematical modeling of two-dimensional correlation functions for different phase-frequency codes of the multifrequency signal; to develop recommendations for the use of low-altitude targets in the radar. The methods used are: methods of statistical radio engineering, probability theory and mathematical statistics. The following results were obtained: time-frequency diagram, amplitude-frequency spectrum, two-dimensional correlation function of uncertainty, as well as normalized autocorrelation and frequency-correlation functions for different phase frequency codes of the multifrequency signal are obtained. The coherence band, the main lobe duration and the side lobe level of the autocorrelation of the impulse multifrequency signals with components without internal modulation and pulsed multifrequency signals with linearly frequency modulated components with different codes in frequency and phase, as well as different widths of the discrete spectrum and their different frequency spacing are analyzed. Conclusions. The comparative analysis of the main types of serial multifrequency signals allows to formulate recommendations regarding their application in the radar for detecting low-altitude targets in various conditions of interference situation is conducted. For example, it is more expedient to use serial multifrequency signals with a continuous amplitude-frequency spectrum to improve the detection characteristics of low-altitude targets in the radar channel over the sea in fluctuation noise. The envelope signals and those ones with a not continuous amplitudefrequency spectrum are more expedient to use under conditions of deliberate time-varying and frequency-non-uniform interference. The serial multifrequency signals with a rectangular envelope and the amplitude-frequency spectrum, which consists of the components of the amplitude-frequency spectrum that intersect, are more suitable for improving the detection of lowaltitude targets over the sea in a radar channel with modulating interference.

Keywords : multifrequency signals, serial pulse multifrequency signals, detection radar, low altitude target, coherence of signals. 